NBER WORKING PAPER SERIES

\title{
HEALTH CARE MARKETS, THE SAFETY NET AND ACCESS TO CARE AMONG THE UNINSURED
}

\author{
Carole Roan Gresenz \\ Jeannette A. Rogowski \\ José J. Escarce \\ Working Paper 10799 \\ http://www.nber.org/papers/w10799
NATIONAL BUREAU OF ECONOMIC RESEARCH
1050 Massachusetts Avenue
Cambridge, MA 02138
September 2004

This study was supported by program project grant P01-HS10770 from the Agency for Healthcare Research and Quality.The views expressed herein are those of the author(s) and not necessarily those of the National Bureau of Economic Research.

(C2004 by Carole Roan Gresenz, and Jeannette A. Rogowski, and José J. Escarce,. All rights reserved. Short sections of text, not to exceed two paragraphs, may be quoted without explicit permission provided that full credit, including $(9$ notice, is given to the source. 
Healthcare Markets, he Safety Net and Access to Care Among the Uninsured

Carole Roan Gresenz, and Jeannette A. Rogowski, and José J. Escarce

NBER Working Paper No. 10799

September 2004

JEL No. I1

\section{ABSTRACT}

We use nationally representative Medical Expenditure Panel Survey (MEPS) data linked with data from multiple secondary sources to study the relationship between access to care among the uninsured and the local healthcare market and safety net. We find that distances between the rural uninsured and safety net providers such as hospital emergency rooms, public hospitals, migrant health centers, public housing primary care programs, and community health centers are significantly associated with utilization of a variety of healthcare services. In urban areas, we find that the capacity of the safety net and the pervasiveness and competitiveness of managed care have a significant relationship with healthcare utilization. Our findings suggest that facilitating transport to safety net providers and increasing the number of such providers are likely to improve access to care among the rural uninsured. By contrast, policies oriented toward enhancing funding for the safety net and increasing the capacity of safety net providers are likely to be important to ensuring access among the urban uninsured.

\section{Carole Roan Gresenz}

RAND Corporation

1200 South Hayes Street

Arlington, VA 22202-5050

gresenz@rand.org

Jeannette A. Rogowski

Department of Health Systems and Policy

School of Public Health

University of Medicine and Dentistry

of New Jersey

jeanette_rogowki@rand.org

\section{José Escarce}

\section{RAND}

1700 Main Street

M-28

Santa Monica, CA 90401

and UCLA, NBER

escarce@rand.org 


\section{Introduction}

In 2002, 15.2 percent of Americans-43.6 million individuals-were uninsured for the full year. While the percentage represents a slight increase over 2001 figures (14.6 percent of the population, 41.2 million individuals), it is not a significant deviation from recent history: In each of the last fifteen years, roughly one in seven individuals in the U.S. (between 12.9 and 16.3 percent of the population) have been uninsured (U.S. Census Bureau, 2003). For many of the uninsured, access to healthcare is heavily dependent on a "safety net" of providers. Such providers include traditional safety net providers—-those who are legally obligated to provide care to persons who cannot afford it, such as public hospitals, federally funded community health centers, and local health departments—and mainstream providers- those who provide uncompensated care voluntarily or as part of their community-service obligation.

Despite the reliance of the uninsured on safety net providers, little is known about whether and how differences in the safety net across communities affect access to care among uninsured. A sole study (Long and Marquis, 1999) reports that uninsured children have more annual visits to physicians in states with higher safety net capacity. Other studies have described wide variation in access to medical care among uninsured individuals living in different communities (Cunningham et al, 1998) and linked differences in access to managed care penetration and the percent of the local population that is uninsured (Cunningham, 1999), but these studies have focused on a limited number of communities This study extends previous research by examining how the structure and capacity of the safety net and healthcare market structure relate to access to care among the uninsured using nationally representative survey data (the Medical Expenditure Panel Survey, MEPS) linked to multiple secondary data sources. 


\section{Conceptual Framework and Hypotheses}

For an uninsured person, the out-of-pocket costs of medical care are largely determined by the costs associated with the time, effort, and stigma of qualifying for discounted or free care and by the available supply of such care. These variables, in turn, are influenced by characteristics of safety net providers in the community and certain dimensions of the healthcare market structure.

Two aspects of the local safety net are likely to be important determinants of access to care: Location of safety net providers and safety net capacity. Especially for low income individuals, the direct and indirect costs associated with travel can strongly influence the utilization of medical care (Acton, 1977). Specifically, we expect that travel costs increase with distance and that the farther individuals live from safety net providers, the lower will be utilization. We also hypothesize that uninsured individuals will be more able to obtain care the better is the overall ability (including number of patients that can be served and range and type of services available) of the safety net to provide needed services. Funding availability is a key determinant of safety net capacity.

Characteristics of the healthcare market structure other than the safety net are also likely to affect utilization. Earlier research (Cunningham, 1999; IOM, 2003) suggests that two aspects of the healthcare market structure - the managed care penetration rate and percentage of the population that is uninsured-bear on access to care among the uninsured. In particular, we hypothesize that a greater presence of managed care may limit the ability of providers to set prices for insured patients that will allow for cross-subsidization of free or discounted care for the uninsured. However, we also hypothesize that competition among managed care plans may erode plans' bargaining power, reducing their control over prices. Thus, in competitive managed 
care markets, providers may be able to negotiate higher prices that enable them to subsidize discounted care for the uninsured. Furthermore, uninsured individuals living in areas where a relatively large fraction of the population is also uninsured may have to compete for limited healthcare resources, and thus healthcare utilization may be lower in these areas for any given uninsured individual. Finally, we expect that access to care among the uninsured is positively influenced by the local supply of primary care doctors. A more dense distribution of such doctors is likely to increase the probability that an uninsured individual is able to find a doctor who provides charity care and is also likely to be associated with more proximate primary care providers and thus a lower time-price of obtaining care.

\section{Data and Methods}

Data

We use data from the MEPS household component (HC) survey linked to data from numerous sources describing the safety net and healthcare market structure. The MEPS HC is a nationally representative survey with detailed information on health status and health services utilization. MEPS uses an overlapping panel design in which respondents are interviewed multiple times over a 30-month period to collect data spanning a two year period. (Additional information about the MEPS design is available in Cohen et al. 1996/97).

To describe the healthcare safety net and market structure in each individual's location, we derived variables from numerous sources including the American Hospital Association (AHA) Annual Survey of Hospitals, Area Resource File (ARF), the InterStudy Regional Market Analysis database, the Bureau of Primary Healthcare Physicians (BPHC) Uniform Data System, the Current Population Survey (CPS), Census of Governments, and the Census Bureau's Annual 
Survey of State and Local Government Finances. ${ }^{1}$ The public-use MEPS files do not contain the geographic location of individuals (with the exception of region and whether or not the individual resides in an MSA). However, through an arrangement with the Agency for Healthcare Research and Quality (AHRQ), we were able to create a limited-use MEPS file that contains variables measured at more refined geographic levels. A major innovation of this research is the calculation of distances from specific individuals to various safety net providers. Study Sample

Our analysis pools MEPS respondents who were uninsured for at least one full calendar year during the period from 1996 to 2000. Each observation represents a one year period of an individual being uninsured; thus, there are two observations for each respondent who was uninsured during both calendar years in which he/she was surveyed. We exclude from analysis respondents under the age of 18 or aged 65 or older, as well as individuals who were ineligible for all or part of the calendar year (such as those who died or were institutionalized during the year). In total, our data include 12,513 observations of full calendar-year episodes of uninsurance from 8,285 respondents. There are roughly two to three thousand observations from each year $(1996=2,099,1997=3,315,1998=2,340,1999=2,294,2000=2,465)$. All analyses are run separately for individuals living in metropolitan statistical areas (MSAs) and non-MSAs. We term the former "urban" uninsured and the latter "rural" uninsured.

\section{Dependent Variables}

We analyze multiple dependent variables measuring different types of healthcare utilization among the uninsured, including number of office-based physician visits, number of office-based non-physician visits, total number of office-based visits, number of emergency 
room visits, medical expenditures (excluding expenditures for dental or vision care), and inpatient hospital nights. ${ }^{2}$ Table 1 provides descriptive statistics for the dependent variables.

\section{Independent Variables}

All specifications include individual demographic characteristics, health status, and the key independent variables of interest - those describing the local safety net and healthcare market. Due to the nature of our data, our ability to characterize the safety net and healthcare market structure is more limited for rural compared to urban areas. For the rural uninsured, we control for the availability of safety net providers and the supply of primary care physicians; the specification for the urban uninsured includes measures of safety net capacity, managed care, and the percentage of people who are uninsured. Tables 2 and 3 provide descriptive statistics for individual-level and market level independent variables, respectively.

Demographic controls include education (high school degree, some college, and college degree; less than high school omitted), household structure (marital status and whether or not the individual lives alone), gender, age (18-24 years, 25-34 years, 45-64 years; 35-44 years omitted), gender-age interactions, race (non-Hispanic black, Hispanic; non-Hispanic white omitted), and family income as a percentage of the federal poverty line (100-200 percent, 200-400 percent, over 400 percent; <100 percent omitted).

We measure health status with variables spanning four domains: (1) functional, cognitive and social limitations (a single indicator for any such limitation) (2) vision/hearing problems (single indicator for any such problem, including blindness or deafness), (3) self-rated health (dichotomous variables for categories very good, good, fair or poor; excellent omitted), and (4) chronic conditions. We constructed indicators for the presence or absence of 25 chronic conditions (such as diabetes, obesity, and asthma) and included specific indicator variables for a 
subset of those conditions and a summary indicator for the presence of any of the remaining conditions.

We account for the location of safety net providers using measures of distances in miles between each individual and the nearest emergency room and public hospital, which were calculated using AHA data (which contains hospitals' exact street address). We also determined the distance between each individual and the nearest of one of three types of federally funded health providers - migrant health center, community health center, or public housing primary care program. These providers all receive funding through the Bureau of Primary Healthcare (BPHC); for the sake of brevity we will often refer to them as "BPHC providers." We approximated individuals' locations using the population centroid of their zipcode because their exact address was unavailable. For sensitivity analyses, we created variables indicating the number of emergency rooms, public hospitals, and BPHC providers within a given distance from individuals. For the urban uninsured, these radius-based measures are constructed using a 5 mile radius, and for those living in rural areas, the radius is 10 miles.

For urban areas, we also measure safety net capacity. We use the level of local expenditures for health and hospitals based on data from the Census of Governments and the Annual Survey of State and Local Government Finances. Examples of public health expenditures include money spent on public health administration, vital statistics, categorical health programs (such as for tuberculosis or socially transmitted diseases), health related inspection and regulation, immunization programs, outpatient health clinics, and alcohol and drug abuse prevention and rehabilitations. Hospital expenditures are for hospital facilities directly administered by the government or institutions for the care and treatment of the handicapped directly administered by the government, or for the provision of hospital care in 
other public or private hospitals and support of such hospitals. Expenditures were converted to 1998 dollars using the medical component of the consumer price index and scaled to the lowincome population (within 200 percent of the poverty line) in the MSA using data from the March CPS.

For the rural and the urban uninsured, we describe the primary care doctor supply in the local area with the sum of family practitioners, internists, and general care practitioners per thousand people in the county (based on ARF data). We further describe the healthcare market in urban areas with variables indicating managed care penetration (specifically, HMO penetration) and competition. These variables are derived from InterStudy data. The penetration measure indicates the percentage of the population in an HMO and the competition measure is one minus the sum of each HMO's market share squared. The competition measure ranges from 0 to 1 where a value near 1 indicates a very competitive market and a value near 0 indicates little competition. Finally, our specification includes the percentage of individuals who are uninsured in the MSA (data are not available for non-MSAs), which is calculated using a three-year moving average derived from CPS data.

\section{Estimation}

All regressions were weighted and adjusted for the complex design of the MEPS survey (Cohen et al, 1996/1997, 1999). We analyze the number of office-based physician and nonphysician visits, total office-based visits, and emergency department visits with a negative binomial regression model (Keeler et al, 1988; Hausman et al. 1984; Cameron and Trivedi, 1986; Kilpatrick, 1977). For medical expenditures and inpatient hospital nights, we use a two-part model of medical care utilization (Blough et al, 1999; Manning et al, 1981, 1987). The first part is an equation for any use and the second part is an equation for the amount of use conditional on 
any use. We use a logistic regression model for the first part. For the second part, we explored a variety of models (Manning and Mullahy, 2000; Burgess et al, 2002). We ultimately chose to model conditional medical expenditures using ordinary least squares (OLS) regression with the $\log$ of expenditures as the dependent variable and where predictions are calculated using a heteroskedastic smearing retransformation. (Manning, 1998; Mullahy, 1998; Duan, 1983; Duan et al, 1983). ${ }^{3}$ We model conditional inpatient nights using a poisson family (in which the variance is assumed to be equal to the mean) generalized linear model with a log link.

\section{Simulations}

We simulated values for the various kinds of utilization using standardized predictions. We performed separate simulations for a range of values of the (rural or urban-specific) distribution of each of the variables describing the safety net or healthcare market structure. Rural and urban simulation values are summarized in Table 4. For the negative binomial regressions, we first obtained parameter estimates using the actual data. We then substituted the simulation value for the actual value of the simulation variable, while retaining the values of all other variables, and predicted utilization with the restyled data. Standard errors for the predictions were calculated using the delta method (Bishop et al, 1975). We used the significance of the coefficient on the simulation variable to determine the significance of differences among predictions.

The simulation process was similar for the two-part models of medical expenditures and inpatient nights. For these variables, we first estimated the parameters of the two parts of the model. Second, we substituted the simulation values for actual values of the simulation variables in both parts of the model and produced predictions. Third, we obtained a prediction of unconditional use by multiplying the predicted probability of any use and the predicted level of 
use conditional on having any use. We used the delta method to derive the standard errors of the unconditional predictions and for the statistical tests of differences between various predicted values.

\section{Results}

\section{Descriptive Data}

With the exception of inpatient admissions, uninsured individuals living in rural areas were more likely to have some versus none of each type of utilization (Table 1). However, the intensity of use conditional on any use was consistently lower among the rural uninsured. In terms of the safety net, as expected, mean distances between the rural uninsured and the nearest safety net providers were larger than those for the urban uninsured (Table 3). Our sensitivity measure of the number of safety net providers within a given radii was also smaller for the rural compared to the urban uninsured, even considering 10 mile radii for those in rural areas and 5 mile radii for those in urban locales.

Multivariate Analyses

Tables 5 and 6 show predicted annual utilization among the rural and urban uninsured, respectively, for simulation values of each of the safety net and healthcare market variables. ${ }^{4}$ As an example of how to interpret the values in these tables, the first row of Table 5 indicates that if all uninsured individuals living in rural areas had an emergency room approximately a mile away (the $25^{\text {th }}$ percentile value of the distribution), the average number of physician visits would be 1.79. By comparison, if the rural uninsured all lived significantly farther away from the ER (13 miles, the $75^{\text {th }}$ percentile value), physician visits would average 1.61 . Tables 7 and 8 report 
predictions for sensitivity analyses using radius-based measures of the availability of safety net providers.

\section{Rural Uninsured}

The analyses of utilization among the rural uninsured provide support for both own-price and cross-price effects of distances to various safety net providers on utilization. We observe an own price effect of distance to the closest migrant health center, community health center or public housing primary care program, with a longer distance resulting in fewer office-based physician visits and consequently fewer total office-based visits and lower medical expenditures. The results are consistent with our hypothesis that a higher time-price of obtaining care from a safety net provider decreases utilization of healthcare among the uninsured. Analyses using the radius-based measure (number of migrant health centers, community health centers, and public housing primary care programs within a 10 mile radius) confirm an association between availability of BPHC providers and physician visits, but also suggest availability is negatively associated with non-physician visits and, consequently, that availability is not associated with either total office-based visits or total expenditures.

We find a cross-price effect of distance to the nearest emergency room on physician visits (and as a result total office-based visits) and inpatient hospital nights. We observe an inverse relationship, with closer distances to the ER associated with more physician visits, total officebased visits, and inpatient hospital nights, suggesting that these services are complementary with use of the ER. Individuals may follow-up an ER visit with a physician visit, perhaps because an ER doctor refers a patient to a provider, while a common path to inpatient hospital stays may be through an ER visit. Surprisingly, while our results show longer distances to the ER are 
associated with fewer ER visits, the relationship is not statistically significant. In a sensitivity analysis, we do find that a greater number of ERs within a 5 mile radius is associated with more ER visits and greater total expenditures, though the sensitivity analysis does not show a significant association with other types of utilization. The positive cross-price effect we observe of distance to the closest public hospital on non-physician visits suggests that the uninsured may substitute use of the public hospital for non-physician office-based visits. Sensitivity analyses with radius-based measures of availability of public hospitals lend further support to the finding.

The radius-based results also suggest that more public hospitals within a 10 mile radius decreases the number of inpatient nights. The finding may reflect a difference in the probability of admission or length of stay conditional on admission when uninsured individuals seek admittance at a public versus a non-public hospital.

Finally, while the main results show no effects of primary care physician supply on utilization among the rural uninsured, the sensitivity analyses show a negative relationship between physician supply and ER visits and between physician supply and total expenditures. The results suggest that a greater physician supply may result in substitution among the uninsured of office-based for ER visits. But, the association between physician supply and office-based visits of all types, while positive, is not significant. A caution is that the measure of supply is a county-level measure which may not adequately capture variation in physician supply that is relevant to the individual, and especially so in rural areas where counties can be very large

\section{Urban Uninsured}

In contrast to the rural uninsured, we do not find pervasive associations between distances to safety net providers and healthcare utilization among the urban uninsured. We find no association between distance to the closest emergency room and any type of utilization, and 
associations between other distances to safety net providers and utilization observed in the continuous distance specifications are not observed when radius-based measures are used. Moreover, observed associations are sometimes counterintuitive. For example, a greater number of ERs within 5 miles is associated with fewer ER visits. One possibility is that while distance is a good proxy for the time-price of obtaining care for the rural uninsured, it may less precisely capture the true time-price of obtaining care for the urban uninsured because of the effects on travel time of mass transit systems and traffic (which we are unable to capture with our data).

However, a key finding for the urban uninsured is the association between the level and nature of managed care in the local market and utilization among the uninsured. The relationship appears across numerous types of utilization, including physician visits (the greater is HMO penetration, the fewer are visits), non-physician visits (the greater is HMO penetration, the more such visits), inpatient hospital nights (greater penetration associated with fewer nights), and medical expenditures (greater penetration associated with lower expenditures). Our results suggest that greater managed care presence shifts utilization among the uninsured away from office-based physician visits and inpatient hospital stays and towards non-physician providers. One possibility is that the uninsured are less able to find charity care from physicians in areas where managed care limits their ability to set prices for insured patients. However, the relationship between HMO penetration and the number of physician visits is attenuated by the competitiveness of the HMO market; specifically, holding HMO penetration constant, higher competitiveness is associated with more physician visits. In competitive managed care markets, doctors may be better able to negotiate prices and thus more able to subsidize discounted care for the uninsured. Corresponding to the findings of fewer (usually costly) inpatient nights, fewer (relatively expensive) physician visits and a greater number of (less expensive) non-physician 
visits in high HMO areas, we find that greater HMO penetration is also associated with lower expenditures. Average expenditures in a low HMO area are 10.7 percent higher compared to those in an urban area with a high HMO penetration.

Other aspects of the healthcare market structure are not completely unrelated to utilization, but the observed associations occur within a limited realm. First, a greater supply of primary care doctors is associated with more inpatient hospital nights, which may reflect a correlation between physician supply and hospital capacity in the urban area (such as number of hospital beds available). Second, the percentage of the population that is uninsured is inversely related to emergency room visits. This finding suggests that uninsured individuals living in areas with many uninsured may compete for limited resources; in particular, emergency room crowding may be a severe problem in areas with many uninsured (Grumbach et al, 1993; Solberg et al., 2003). Though not statistically significant, the simulation results suggest a similar story for physician visits (negative relationship between percent uninsured in the area and average physician visits).

A noteworthy finding pertains to the relationship between the safety net and access to care among the urban uninsured. Thus we find that a greater safety net capacity, as measured by public health expenditures, is associated with more non-physician visits and higher total medical expenditures. These results are consistent with our hypothesis that greater safety net capacity promotes with higher levels of healthcare utilization by the uninsured.

\section{Additional Sensitivity Analyses}

For the urban uninsured, we compared the reported analyses to those omitting the HMO index of competition and our results were robust to this change. In addition, we included a 
measure of the density of the population in the area and also a measure of the distance to the nearest public hospital or teaching hospital (COTH, or Council of Teaching Hospitals), but dropped these variables because they consistently showed no association with utilization.

\section{Conclusions}

While previous research has documented that the amount of healthcare uninsured individuals receive varies significantly depending on where they live, little is known about the factors underlying the differences in healthcare utilization. This study finds that features of the local healthcare market and safety net explain some of the variation in access to care among the uninsured, and moreover, that the specific healthcare market and safety net features that are associated with utilization themselves vary depending on the type of community (urban or rural).

Specifically, we find that among the rural uninsured, the location of safety net providers is a key factor related to healthcare use. For the urban uninsured, we confirm and extend earlier work (Cunningham et al, 1998) reporting lower access to care among the urban uninsured living in areas where managed care penetration is high. Our study further finds that the influence of managed care is diminished, and correspondingly levels of health services use among the uninsured are higher, in more versus less competitive managed care markets. We also find less use of emergency services among the uninsured living in urban areas where a relatively large fraction of the population is also uninsured, corroborating recent IOM work on the effects of uninsurance on communities (IOM, 2003). A novel finding is that greater safety net capacity is significantly (positively) related to the ability of the uninsured to obtain care in urban areas and to expenditures for medical care. 
Several limitations of this research should be noted. First, this study analyzed individuals who were uninsured for a full calendar year. From other research, we know that the population of uninsured individuals is heterogeneous, with some "chronically" uninsured and some individuals who quickly transition between insured and uninsured states (Swartz and McBride, 1990; Monheit and Schur, 1988). Whether patterns of utilization differ for these different groups of uninsured is an open question, as is whether the relationships between features of the healthcare market and safety net and utilization vary amongst these groups of uninsured.

Methodologically, the calculation of individual-specific distances to safety net providers is an important contribution of this research. It represents a step in understanding the link between characteristics of the local community and individual specific outcomes like utilization. But, a limitation is our ability to capture travel time for the urban uninsured. Distance in miles to providers may be a reasonable proxy for travel time for the rural uninsured, but it may be less so for the urban uninsured, where travel times are likely to depend heavily on traffic patterns and the service areas of mass transit systems.

A well-developed literature shows that lack of health insurance has substantial repercussions on both access to healthcare and health status (IOM, 2002). Among the findings are that, compared to the insured, the uninsured are less likely to visit a physician, have a usual source of care, or be admitted to a hospital; are more likely to receive care in hospital outpatient department or emergency room, to have unmet medical needs; and have lower annual medical expenditures and higher mortality (Cunningham, 1999; Newachek et al, 1998; Marquis and Long, 1994/95; Hafner-Eaton, 1993; Franks et al, 1993; Spillman, 1992; Weissman et al, 1992 ; Hadley et al, 1991; Young et al, 1991; Weissman et al, 1989; Lurie et al, 1984). 
Absent the universal provision of health insurance, policy approaches to alleviating the barriers to access facing the uninsured include incremental efforts to increase the affordability and availability of public or private health insurance as well as measures to increase the accessibility of healthcare for the remaining uninsured. Our findings shed light on areas of focus for the latter class of measures. Specifically, facilitating transport to safety net providers and increasing the number of such providers are likely to improve access to care among the rural uninsured. By contrast, policies oriented toward enhancing funding for the safety net and increasing the capacity of safety net providers are likely to be much more important to ensuring access among the urban uninsured. Researchers have reported a relatively stable trend in safety net capacity in the late 1990s through 2001 (Felland et al, 2003), but the absolute level of capacity has been shown to vary widely across communities (Marquis et al, 2004) and some research suggests that those disparities may be widening over time (Hoadley et al, 2004). In addition, increasing budgetary pressures at the federal level and in many states are likely to pose an increasing threat to safety net funding. The HMO findings suggest that particular attention be paid to the uninsured living in areas where many of those insured are covered by managed care, and especially so where little competition among managed care organizations exists. Ironically, the "backlash" against managed care may result in improved access to care for some uninsured (Robinson, 2004), although the salutary effects would be offset to the extent that the backlash also results in increasing healthcare costs, greater numbers of uninsured, and more competition for healthcare resources. 


\section{References}

Acton, J.P. 1977. Demand for Health Care Among the Urban Poor, with Special Emphasis on the Role of Time. In: The Role of Health Insurance in the Health Services Sector. Santa Monica, California : RAND Corporation.

Bishop, T., S. Fineberg, and P. Holland. 1975. Discrete Multivariate Analysis. Cambridge, Deleted: II

Massachusetts: MIT Press.

Blough, D.K., C.W. Madden, and M.C. Hornbrook. 1999. Modeling Risk Using Generalized Linear Models. Journal of Health Economics 18:153-71.

Burgess, J.F., C.L. Christiansen, and W.G. Manning. July 29, 2002. Practical Risk Adjustment for Paying Health Care Providers - Is the Cream that is Skimmed Credible or Must We Shrink from Normal Deviations? Monograph.

Cameron, A.C., and P.K. Trivedi. 1986. Econometric Models Based on Count Data: Comparisons and Applications of Some Estimators and Tests. Journal of Applied Econometrics $1: 29-53$.

Cohen, J.W., A.C. Monheit, K.M. Beauregard, S.B. Cohen, D.C. Lefkowitz, D.E.B. Potter, J.P. Sommers, A.K. Taylor, and R.H. Arnett. 1996 - 1997. The Medical Expenditure Panel Survey: A National Health Information Resource. Inquiry 33:373-89. 
Cohen, S. B., R. DiGaetano, and H. Goksel. 1999. Estimation Procedures in the 1996 MEPS Household Component. Rockville, Maryland: Agency for Health Care Policy and Research. MEPS Methodology Report No. 5. AHCPR PUB. No. 99-0027.

Cunningham, P.J. April 1999. Pressures on Safety Net Access: The Level of Managed Care Penetration and Uninsurance Rate in the Community. Health Services Research 34(1)2: 255-70.

Cunningham, P. J., and P. Kemper. September 9, 1998. Ability to Obtain Medical Care for the Uninsured. Journal of the American Medical Association 280 (10): 921-27.

Duan, N. September 1983. Smearing Estimate: A Nonparametric Retransformation Method. Journal of American Statistical Association 78(383):605-10.

Duan, N., W.G. Manning, C.N. Morris, and J.P. Newhouse. 1983. A Comparison of Alternative Models for the Demand for Medical Care. Journal of Business and Economic Statistics 1:11526.

Felland, L.E., C. S. Lesser, A. B. Staiti, A. Katz, and P. Lichiello. February 2003. The Resilience of the Health Care Safety Net, 1996-2001. Health Services Research 38(1): 489-502.

Franks, P., C.M. Clancy, and M.R. Gold. 1993. Health Insurance and Mortality: Evidence from a National Cohort. Journal of American Medical Association 270: 737-41. 
Grumbach, K., D. Keane, and A. Bindman. 1993. Primary Care and Public Emergency

Department Overcrowding. American Journal of Public Health 83(3):372-8.

Hadley, J., E.P. Steinberg, and J. Feder. 1991. Comparison of Uninsured and Privately Insured Hospital Patients: Condition on Admission, Resource Use, and Outcome. Journal of the American Medical Association 265:374-79.

Hafner-Eaton, C. 1993. Physician Utilization Disparities Between the Uninsured and Insured. Journal of the American Medical Association 269:787-92.

Hausman, J., B.H. Hall, and Z. Griliches. 1984. Econometric Models for Count Data with an Application to the Patents—R\&D Relationship. Econometrica 52:909-38.

Hoadley, J.F., L.E. Felland, and A. Staiti. May 5, 2004. Federal Aid Strengthens Health Care Safety Net: The Strong Get Stronger. Issue Brief No. 80.

Institute of Medicine (IOM). March 2003. A Shared Destiny: Community Effects of Uninsurance. National Academies Press.

Institute of Medicine (IOM). 2002. Care Without Coverage: Too Little, Too Late. National Academies Press. 
Keeler, E.B., J. Buchanan, J. E. Rolph, J. M. Hanley, and D. Reboussin. 1988. The Demand for Episodes of Medical Treatment in the Health Insurance Experiment. R-3454-HHS. Santa Monica, California: RAND Corporation.

Kilpatrick, S.J. 1977. An Empirical Study of the Distribution of Episodes of Illness Recorded in the 1970-71 National Morbidity Survey. Applied Statistics 26:26-33.

Long, S.H., and M.S. Marquis. 1999. Geographic Variation in Physician Visits for Uninsured Children: The Role of the Safety Net. Journal of the American Medical Association 281:2035-

40.

Lurie, N., N. B. Ward, M. F. Shapiro, and R. H. Brook. 1984. Termination from Medi-Cal: Does it Affect Health? New England Journal of Medicine 311:480-84.

Manning, W.G., C.N. Morris, J.P. Newhouse, L.L. Orr, N. Duan, E.B. Keeler, A. Leibowitz, K.H. Marquis, M.S. Marquis, and C.E. Phelps. 1981. A Two Part Model of the Demand for Medical Care: Preliminary Results from Health Insurance Study. In Health, Economics, and Health Economics, edited by J. van Der Gaag and M. Perlman, 103-23. Amsterdam: North Holland.

Manning, W.G., J.P. Newhouse, N. Duan, E.B. Keeler, A. Leibowitz, and M.S. Marquis. 1991. Health Insurance and the Demand for Medical Care: Evidence from Randomized Experiment. American Economic Review 77: 251-78. 
Manning, W.G. 1998. The Logged Dependent Variable, Heteroskedasticity, and the Retransformation Problem. Journal of Health Economics 17:283-95.

Manning, W.G., and J. Mullahy. 2001. Estimating Log Models: To Transform or Not to Transform? Journal of Health Economics 20(4): 461-94.

Marquis, M.S., and S.H. Long. 1994/1995. The Uninsured Access Gap: Narrowing the Estimates. Inquiry 31: 405-14.

Marquis, M.S., J.A. Rogowski, and J.J. Escarce. May 2004. Recent Trends and Geographic Variation in the Safety Net. Medical Care 42(5) 408-15.

Mullahy, J. 1998. Much Ado About Two: Reconsidering Retransformation in the Two-Part Model in Health Econometrics. Journal of Health Economics 17:247-81.

Monheit, A.C., and C.L. Schur. 1988. The Dynamics of Health Insurance Loss: A Tale of Two Cohorts. Inquiry 25:315-17.

Newacheck, P. W., J. J. Stoddard, D. C. Hughes, and M. Pearl. 1998. Health Insurance and Access to Primary Care for Children. New England Journal of Medicine 338:513-19. 
Robinson, J.C. 2004. Reinvention of Health Insurance in the Consumer Era. Journal of the American Medical Association 291(15):1880-6.

Solberg, L.I., B.R. Asplin, R.M. Weinick, and D.J. Magid. 2003. Emergency Department Crowding: Consensus Development of Potential Measures. Annals of Emergency Medicine 42(6):824-34.

Spillman, B.C. Winter 1992. The Impact of Being Uninsured on Utilization of Basic Health Care Services. Inquiry 29(4):457-66.

Swartz, K., and T. D. McBride. 1990. Spells Without Health Insurance: Distributions of Durations and their Link to Point-in-Time Estimates of the Uninsured. Inquiry 27:281-88.

Weissman, J.S., C. Gatsonis, and A.M. Epstein. 1992. Rates of Avoidable Hospitalization by Insurance Status in Massachusetts and Maryland. Journal of the American Medical Association 268: 2388-94.

Weissman, J., and A.M. Epstein. 1989. Case Mix and Resource Utilization by Uninsured Hospital Patients in the Boston Metropolitan Area. Journal of the American Medical Association 261:3572-76.

U.S. Census Bureau. September 2003. Health Insurance Coverage in the United States (2002). Available at www.census.gov/prod/2003pubs/p60-223.pdf (accessed May 13, 2004). 
Young, G.J., and B.B. Cohen. 1991. Inequities in Hospital Care: The Massachusetts Experience.

Inquiry 28:255-62. 
Table 1: Utilization Among Full-Year Uninsured Adults by Location

\begin{tabular}{lcccc}
\hline & \multicolumn{2}{c}{ Rural } & \multicolumn{2}{c}{ Urban } \\
Type of Utilization & Mean & Std Err & Mean & Std Err \\
\hline \# office-based physician visits & 1.49 & $(0.07)$ & 1.44 & $(0.06)$ \\
$\quad$ Proportion with any office-based physician visit & 0.42 & $(0.01)$ & 0.36 & $(0.01)$ \\
$\quad$ \# office-based physician visits given $>0$ & 3.54 & $(0.15)$ & 3.96 & $(0.14)$ \\
& & & & \\
\# office-based non-physician visits & 0.69 & $(0.07)$ & 0.76 & $(0.06)$ \\
$\quad$ Proportion with any office-based non-physician visits & 0.18 & $(0.01)$ & 0.13 & $(0.00)$ \\
$\quad$ \# office-based non-physician visits given $>0$ & 3.86 & $(0.35)$ & 5.90 & $(0.41)$ \\
& & & & \\
\# total office-based visits & 2.18 & $(0.10)$ & 2.20 & $(0.09)$ \\
$\quad$ Proportion with any office-based visit & 0.48 & $(0.01)$ & 0.40 & $(0.01)$ \\
$\quad$ \# total office-based visits, given $>0$ & 4.58 & $(0.20)$ & 5.44 & $(0.21)$ \\
& & & & \\
\# emergency room visits & 0.17 & $(0.01)$ & 0.15 & $(0.01)$ \\
$\quad$ Proportion with any emergency room visit & 0.13 & $(0.01)$ & 0.11 & $(0.00)$ \\
$\quad$ \# emergency room visits, given $>0$ & 1.31 & $(0.05)$ & 1.37 & $(0.03)$ \\
& & & & \\
\# of inpatient hospital nights & 0.23 & $(0.05)$ & 0.25 & $(0.03)$ \\
$\quad$ Proportion with any inpatient admission & 0.04 & $(0.00)$ & 0.04 & $(0.00)$ \\
$\quad$ \# of inpatient nights, given $>0$ & 5.93 & $(1.29)$ & 6.61 & $(0.75)$ \\
& & & & \\
Total medical expenditures & 603.7 & $(37.93)$ & 599.4 & $(32.01)$ \\
$\quad$ Proportion with any medical expenditures & 0.59 & $(0.01)$ & 0.50 & $(0.01)$ \\
$\quad$ Medical expenditures, given $>0$ & 1022.0 & $(61.15)$ & 1193.1 & $(61.78)$ \\
\hline
\end{tabular}


Table 2: Individual Level Independent Variables

\begin{tabular}{|c|c|c|c|c|}
\hline \multirow[b]{2}{*}{ Individual Level Variable } & \multicolumn{2}{|c|}{ Rural } & \multicolumn{2}{|c|}{ Urban } \\
\hline & Mean & Std Err & Mean & Std Err \\
\hline Less than high school & 0.33 & $(0.01)$ & 0.31 & $(0.01)$ \\
\hline High school graduate or GED & 0.44 & $(0.01)$ & 0.40 & $(0.01)$ \\
\hline Some college & 0.17 & $(0.01)$ & 0.19 & $(0.01)$ \\
\hline College graduate & 0.06 & $(0.01)$ & 0.11 & $(0.00)$ \\
\hline Married & 0.47 & $(0.01)$ & 0.37 & $(0.01)$ \\
\hline Widowed/divorced/separated & 0.23 & $(0.01)$ & 0.20 & $(0.01)$ \\
\hline Live alone & 0.15 & $(0.01)$ & 0.18 & $(0.01)$ \\
\hline Aged 18-24 & 0.18 & $(0.01)$ & 0.21 & $(0.01)$ \\
\hline Aged 25-34 & 0.26 & $(0.01)$ & 0.28 & $(0.01)$ \\
\hline Aged 35-44 & 0.27 & $(0.01)$ & 0.25 & $(0.01)$ \\
\hline Aged 45-64 & 0.30 & $(0.01)$ & 0.26 & $(0.01)$ \\
\hline Female & 0.47 & $(0.01)$ & 0.43 & $(0.01)$ \\
\hline Black & 0.13 & $(0.01)$ & 0.17 & $(0.01)$ \\
\hline Hispanic & 0.11 & $(0.02)$ & 0.29 & $(0.01)$ \\
\hline Other (non-White) & 0.03 & $(0.00)$ & 0.05 & $(0.01)$ \\
\hline Income $<$ poverty & 0.25 & $(0.01)$ & 0.21 & $(0.01)$ \\
\hline Income $1-2 x$ poverty & 0.33 & $(0.01)$ & 0.30 & $(0.01)$ \\
\hline Income $2-4 x$ poverty & 0.29 & $(0.01)$ & 0.30 & $(0.01)$ \\
\hline Income $>4 x$ poverty & 0.13 & $(0.01)$ & 0.19 & $(0.01)$ \\
\hline Nonorganic psychoses & 0.02 & $(0.00)$ & 0.02 & $(0.00)$ \\
\hline Arthropathies & 0.04 & $(0.00)$ & 0.03 & $(0.00)$ \\
\hline Asthma & 0.03 & $(0.00)$ & 0.03 & $(0.00)$ \\
\hline Depression & 0.06 & $(0.01)$ & 0.06 & $(0.00)$ \\
\hline Diabetes & 0.03 & $(0.00)$ & 0.03 & $(0.00)$ \\
\hline Disease of lipoid metabolism & 0.02 & $(0.00)$ & 0.02 & $(0.00)$ \\
\hline Hypertension & 0.08 & $(0.01)$ & 0.06 & $(0.00)$ \\
\hline Migraine & 0.03 & $(0.00)$ & 0.02 & $(0.00)$ \\
\hline Thyroid disorder & 0.01 & $(0.00)$ & 0.01 & $(0.00)$ \\
\hline Other chronic condition & 0.04 & $(0.00)$ & 0.03 & $(0.00)$ \\
\hline Functional limitation & 0.09 & $(0.01)$ & 0.06 & $(0.00)$ \\
\hline Social limitation & 0.04 & $(0.00)$ & 0.03 & $(0.00)$ \\
\hline Cognitive limitation & 0.03 & $(0.00)$ & 0.02 & $(0.00)$ \\
\hline Hearing problem & 0.05 & $(0.01)$ & 0.04 & $(0.00)$ \\
\hline Vision problem & 0.08 & $(0.01)$ & 0.05 & $(0.00)$ \\
\hline Excellent self-rated health & 0.28 & $(0.01)$ & 0.28 & $(0.01)$ \\
\hline Very good self-rated health & 0.26 & $(0.01)$ & 0.30 & $(0.01)$ \\
\hline Good self-rated health & 0.30 & $(0.01)$ & 0.29 & $(0.01)$ \\
\hline Fair self-rated health & 0.12 & $(0.01)$ & 0.10 & $(0.00)$ \\
\hline Poor self-rated health & 0.04 & $(0.00)$ & 0.03 & $(0.00)$ \\
\hline
\end{tabular}


Table 3: Market Level Independent Variables

\begin{tabular}{lcccc}
\hline & \multicolumn{2}{c}{ Rural } & \multicolumn{2}{c}{ Urban } \\
Market Level Variable & Mean & Std Err & Mean & Std Err \\
\hline Miles to nearest ER & 8.88 & $(0.47)$ & 3.68 & $(0.09)$ \\
Miles to nearest public hospital & 24.54 & $(1.24)$ & 17.49 & $(0.57)$ \\
Miles to nearest BPHC provider & 30.93 & $(1.48)$ & 12.61 & $(0.58)$ \\
\# of ERs within 10 miles & 0.71 & $(0.02)$ & $*$ & \\
\# of public hospitals within 10 miles & 0.29 & $(0.03)$ & $*$ & \\
\# BPHC providers within 10 miles & 0.36 & $(0.05)$ & $*$ & \\
\# of primary care doctors per 1k persons & 0.38 & $(0.01)$ & 0.63 & $(0.07)$ \\
\# ERs within 5 miles & $*$ & & 3.12 & $(0.08)$ \\
\# public hospitals within 5 miles & $*$ & & 0.43 & $(0.02)$ \\
\# BPHC providers within 5 miles & $*$ & & 3.64 & $(0.17)$ \\
HMO penetration rate & $*$ & & 0.31 & $(0.01)$ \\
HMO index of competition & $*$ & & 0.71 & $(0.01)$ \\
Public health \$ per low income population & $*$ & & $\$ 744$ & $(22)$ \\
Percent uninsured & $*$ & & 0.20 & $(0.00)$ \\
\hline
\end{tabular}

*Not applicable 
Table 4: Simulation Values for Rural and Urban Uninsured

\begin{tabular}{|c|c|c|c|}
\hline Simulation Variable & Value & Rural & Urban \\
\hline \multirow[t]{3}{*}{ Miles to ER } & $25^{\text {th }}$ percentile & 1.31 & 1.33 \\
\hline & Mean & 8.88 & 3.68 \\
\hline & $75^{\text {th }}$ percentile & 12.98 & 4.43 \\
\hline \multirow[t]{3}{*}{ Miles to public hospital } & $25^{\text {th }}$ percentile & 6.71 & 4.71 \\
\hline & Mean & 24.54 & 17.49 \\
\hline & $75^{\text {th }}$ percentile & 34.38 & 23.12 \\
\hline \multirow[t]{3}{*}{ Miles to BPHC provider } & $25^{\text {th }}$ percentile & 13.35 & 2.35 \\
\hline & Mean & 30.94 & 12.61 \\
\hline & $75^{\text {th }}$ percentile & 44.68 & 15.66 \\
\hline \multirow[t]{3}{*}{ \# ERs within 5 miles (urban)/ 10 miles (rural) } & $25^{\text {th }}$ percentile & 1 & 0 \\
\hline & Median & 2 & $1^{\wedge}$ \\
\hline & $75^{\text {th }}$ percentile & 4 & 1 \\
\hline \multirow[t]{3}{*}{ \# public hospitals within 5 miles (urban)/10 miles (rural) } & $25^{\text {th }}$ percentile & 0 & 0 \\
\hline & Median & $0^{\wedge}$ & $0^{\wedge}$ \\
\hline & $75^{\text {th }}$ percentile & 1 & 1 \\
\hline \multirow[t]{3}{*}{ \# BPHC providers within 5 miles (urban)/ 10 miles (rural) } & $25^{\text {th }}$ percentile & 0 & 0 \\
\hline & Median & $0^{\wedge}$ & $0^{\wedge}$ \\
\hline & $75^{\text {th }}$ percentile & 3 & $1^{\dagger}$ \\
\hline \multirow[t]{3}{*}{ Primary care doctors per $1 \mathrm{k}$} & $25^{\text {th }}$ percentile & 0.26 & 0.46 \\
\hline & Mean & 0.38 & 0.63 \\
\hline & $75^{\text {th }}$ percentile & 0.49 & 0.74 \\
\hline \multirow[t]{3}{*}{ HMO penetration rate } & $25^{\text {th }}$ percentile & $*$ & 0.22 \\
\hline & Mean & $*$ & 0.31 \\
\hline & $75^{\text {th }}$ percentile & $*$ & 0.43 \\
\hline \multirow[t]{3}{*}{ HMO index of competition } & $25^{\text {th }}$ percentile & $*$ & 0.67 \\
\hline & Mean & $*$ & 0.71 \\
\hline & $75^{\text {th }}$ percentile & $*$ & 0.83 \\
\hline \multirow[t]{3}{*}{ Percent uninsured } & $25^{\text {th }}$ percentile & * & 0.15 \\
\hline & Mean & $*$ & 0.20 \\
\hline & $75^{\text {th }}$ percentile & $*$ & 0.25 \\
\hline \multirow{3}{*}{$\begin{array}{l}\text { Public health expenditures } \\
\text { (per low income population) }\end{array}$} & $25^{\text {th }}$ percentile & * & 307 \\
\hline & Mean & $*$ & 744 \\
\hline & $75^{\text {th }}$ percentile & & 900 \\
\hline
\end{tabular}




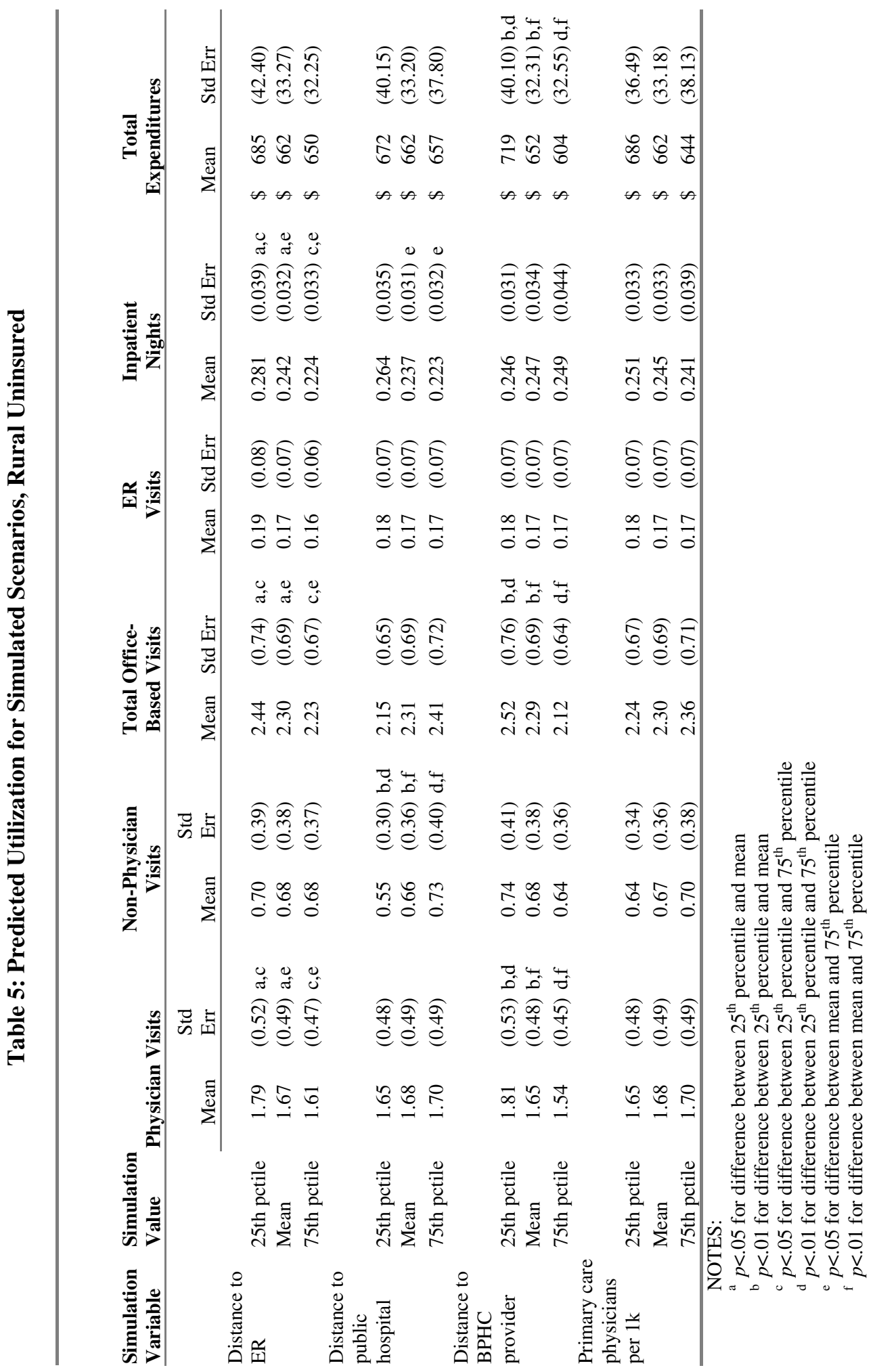


Table 6: Predicted Utilization for Simulated Scenarios, Urban Uninsured

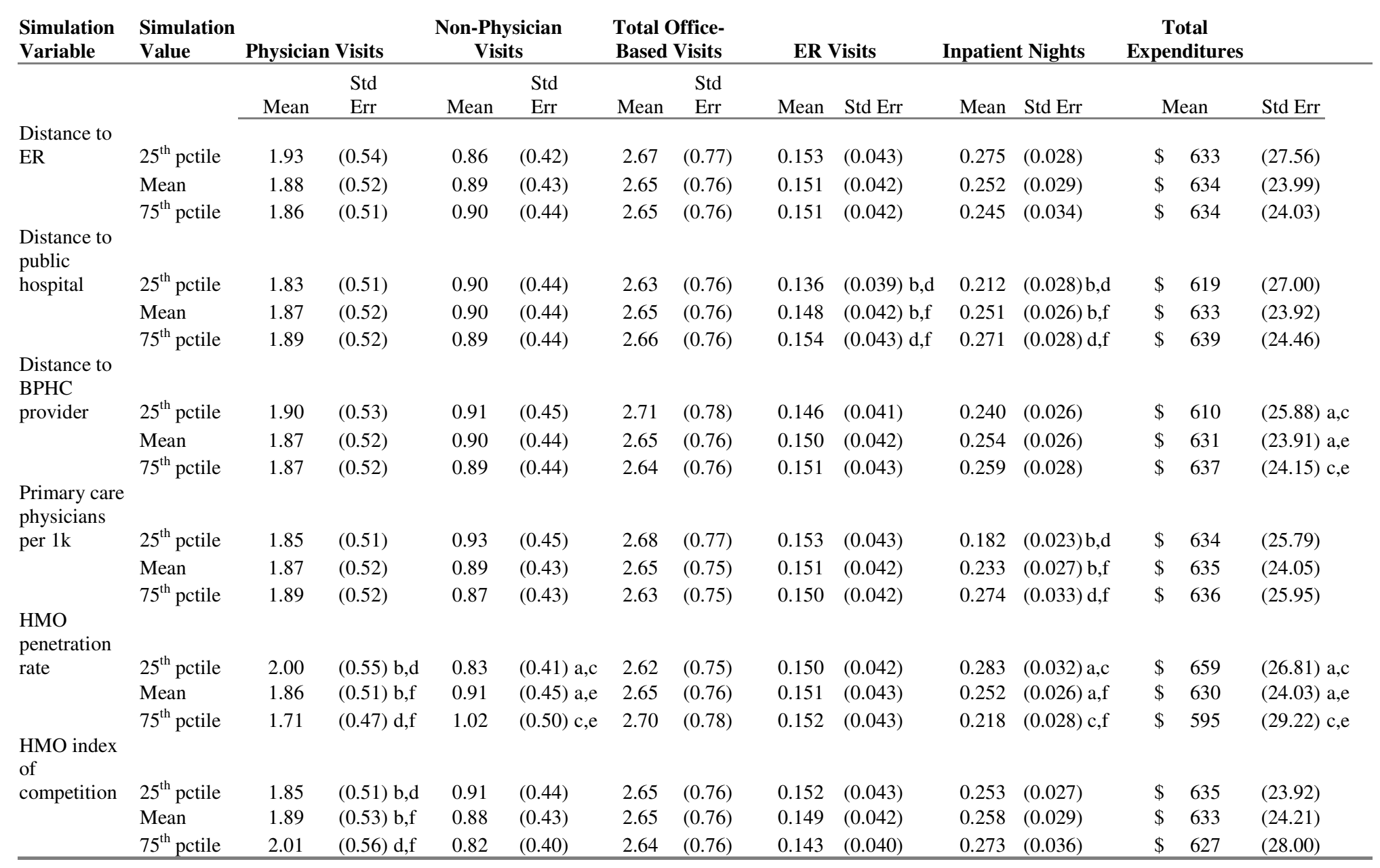




\begin{tabular}{|c|c|c|c|c|c|c|c|c|c|c|c|c|c|c|}
\hline \multirow[t]{3}{*}{$\begin{array}{l}\text { Public health } \\
\text { expenditures }\end{array}$} & 25th pctile & 1.93 & $(0.54)$ & 0.77 & $(0.38) \mathrm{b}, \mathrm{d}$ & 2.55 & $(0.73)$ & 0.148 & $(0.042)$ & 0.238 & $(0.031)$ & $\$$ & 600 & (26.28) b,d \\
\hline & Mean & 1.87 & $(0.52)$ & 0.90 & $(0.44) b, f$ & 2.66 & $(0.76)$ & 0.151 & $(0.042)$ & 0.257 & $(0.027)$ & $\$$ & 637 & $(24.33) b, f$ \\
\hline & 75th pctile & 1.84 & $(0.51)$ & 0.95 & $(0.46) \mathrm{d}, \mathrm{f}$ & 2.70 & $(0.77)$ & 0.152 & $(0.043)$ & 0.264 & (0.027) & $\$$ & 650 & (25.93) d,f \\
\hline \multirow[t]{3}{*}{$\begin{array}{l}\text { Percent } \\
\text { uninsured }\end{array}$} & 25th pctile & 1.86 & $(0.52)$ & 0.90 & $(0.44)$ & 2.62 & $(0.76)$ & 0.163 & $(0.047) \mathrm{a}, \mathrm{c}$ & 0.240 & (0.033) & $\$$ & 656 & (31.94) \\
\hline & Mean & 1.87 & $(0.52)$ & 0.89 & $(0.44)$ & 2.66 & $(0.76)$ & 0.148 & $(0.042) \mathrm{a}, \mathrm{e}$ & 0.258 & $(0.027)$ & $\$$ & 631 & (24.04) \\
\hline & 75th pctile & 1.89 & $(0.53)$ & 0.88 & $(0.44)$ & 2.68 & (0.78) & 0.136 & $(0.039) \mathrm{c}, \mathrm{e}$ & 0.273 & $(0.030)$ & $\$$ & 611 & (26.73) \\
\hline
\end{tabular}

\section{NOTES:}

${ }^{\mathrm{a}} p<.05$ for difference between $25^{\text {th }}$ percentile and mean

b $p<.01$ for difference between $25^{\text {th }}$ percentile and mean

$c \quad p<.05$ for difference between $25^{\text {th }}$ percentile and $75^{\text {th }}$ percentile

${ }^{d} p<.01$ for difference between $25^{\text {th }}$ percentile and $75^{\text {th }}$ percentile

e $p<.05$ for difference between mean and $75^{\text {th }}$ percentile

${ }^{\mathrm{f}} p<.01$ for difference between mean and $75^{\text {th }}$ percentile 
Table 7: Predicted Utilization for Simulated Scenarios Using Radius-Based Measures of Provider Availability, Rural Uninsured

\begin{tabular}{|c|c|c|c|c|c|c|c|c|c|c|c|c|c|c|}
\hline \multirow{3}{*}{$\begin{array}{l}\begin{array}{l}\text { Simulation } \\
\text { Variable }\end{array} \\
\\
\text { \# ERs within } 10 \\
\text { miles }\end{array}$} & \multirow{3}{*}{$\begin{array}{l}\begin{array}{l}\text { Simulation } \\
\text { Value }\end{array} \\
\\
25^{\text {th }} \text { pctile } \\
75^{\text {th }} \text { pctile }\end{array}$} & \multirow{2}{*}{\multicolumn{2}{|c|}{$\begin{array}{l}\text { Physician Visits } \\
\text { Mean Std Err }\end{array}$}} & \multicolumn{2}{|c|}{$\begin{array}{c}\text { Non-Physician } \\
\text { Visits }\end{array}$} & \multicolumn{2}{|c|}{$\begin{array}{l}\text { Total Office } \\
\text { Based Visits }\end{array}$} & \multicolumn{2}{|c|}{ ER Visits } & \multicolumn{2}{|c|}{ Inpatient Nights } & \multicolumn{3}{|c|}{$\begin{array}{c}\text { Total } \\
\text { Expenditures }\end{array}$} \\
\hline & & & & Mean & $\begin{array}{l}\text { Std } \\
\text { Err }\end{array}$ & Mean & $\begin{array}{l}\text { Std } \\
\text { Err }\end{array}$ & Mean & Std Err & Mean & Std Err & & lean & Std Err \\
\hline & & $\begin{array}{l}1.48 \\
1.76\end{array}$ & $\begin{array}{l}(0.45) \mathrm{c} \\
(0.52) \mathrm{c}\end{array}$ & $\begin{array}{l}0.71 \\
0.63\end{array}$ & $\begin{array}{l}(0.38) \\
(0.33)\end{array}$ & $\begin{array}{l}2.16 \\
2.34\end{array}$ & $\begin{array}{l}(0.66) \\
(0.71)\end{array}$ & $\begin{array}{l}0.13 \\
0.19\end{array}$ & $\begin{array}{l}(0.05) \mathrm{d} \\
(0.07) \mathrm{d}\end{array}$ & $\begin{array}{l}0.19 \\
0.30\end{array}$ & $\begin{array}{l}(0.03) \mathrm{d} \\
(0.04) \mathrm{d}\end{array}$ & $\begin{array}{l}\$ \\
\$\end{array}$ & $\begin{array}{l}595 \\
713\end{array}$ & $\begin{array}{l}(44.19) \mathrm{c} \\
(45.44) \mathrm{c}\end{array}$ \\
\hline $\begin{array}{l}\text { \# Public } \\
\text { hospitals } \\
\text { within10 miles }\end{array}$ & $\begin{array}{l}25^{\text {th }} \text { pctile } \\
75^{\text {th }} \text { pctile }\end{array}$ & $\begin{array}{l}1.73 \\
1.56\end{array}$ & $\begin{array}{l}(0.51) \\
(0.48)\end{array}$ & $\begin{array}{l}0.72 \\
0.49\end{array}$ & $\begin{array}{l}(0.38) \mathrm{c} \\
(0.27) \mathrm{c}\end{array}$ & $\begin{array}{l}2.41 \\
1.99\end{array}$ & $\begin{array}{l}(0.73) \\
(0.62)\end{array}$ & $\begin{array}{l}0.18 \\
0.16\end{array}$ & $\begin{array}{l}(0.07) \\
(0.06)\end{array}$ & $\begin{array}{l}0.29 \\
0.20\end{array}$ & $\begin{array}{l}(0.04) \mathrm{d} \\
(0.03) \mathrm{d}\end{array}$ & $\begin{array}{l}\$ \\
\$\end{array}$ & $\begin{array}{l}694 \\
620\end{array}$ & $\begin{array}{l}(43.41) \\
(51.67)\end{array}$ \\
\hline $\begin{array}{l}\text { \# BPHC } \\
\text { providers within } \\
10 \text { miles }\end{array}$ & $\begin{array}{l}25^{\text {th }} \text { pctile } \\
75^{\text {th }} \text { pctile }^{\wedge}\end{array}$ & $\begin{array}{l}1.61 \\
1.77\end{array}$ & $\begin{array}{l}(0.47) \mathrm{c} \\
(0.53) \mathrm{c}\end{array}$ & $\begin{array}{l}0.69 \\
0.56\end{array}$ & $\begin{array}{l}(0.36) \mathrm{c} \\
(0.29) \mathrm{c}\end{array}$ & $\begin{array}{l}2.26 \\
2.32\end{array}$ & $\begin{array}{l}(0.68) \\
(0.70)\end{array}$ & $\begin{array}{l}0.18 \\
0.17\end{array}$ & $\begin{array}{l}(0.07) \\
(0.07)\end{array}$ & $\begin{array}{l}0.22 \\
0.29\end{array}$ & $\begin{array}{l}(0.03) \mathrm{d} \\
(0.04) \mathrm{d}\end{array}$ & $\begin{array}{l}\$ \\
\$\end{array}$ & $\begin{array}{l}663 \\
689\end{array}$ & $\begin{array}{l}(40.25) \\
(36.77)\end{array}$ \\
\hline $\begin{array}{l}\text { Primary care } \\
\text { physicians per } \\
1 \mathrm{k}\end{array}$ & $\begin{array}{l}25^{\text {th }} \text { pctile } \\
\text { Mean } \\
75^{\text {th }} \text { pctile }\end{array}$ & $\begin{array}{l}1.67 \\
1.68 \\
1.68\end{array}$ & $\begin{array}{l}(0.49) \\
(0.50) \\
(0.50)\end{array}$ & $\begin{array}{l}0.63 \\
0.65 \\
0.68\end{array}$ & $\begin{array}{l}(0.33) \\
(0.34) \\
(0.35)\end{array}$ & $\begin{array}{l}2.23 \\
2.28 \\
2.32\end{array}$ & $\begin{array}{l}(0.67) \\
(0.68) \\
(0.70)\end{array}$ & $\begin{array}{l}0.19 \\
0.17 \\
0.16\end{array}$ & $\begin{array}{l}(0.07) \mathrm{a}, \mathrm{c} \\
(0.07) \mathrm{a}, \mathrm{e} \\
(0.06) \mathrm{c}, \mathrm{e}\end{array}$ & $\begin{array}{l}0.26 \\
0.26 \\
0.25\end{array}$ & $\begin{array}{l}(0.04) \\
(0.04) \\
(0.04)\end{array}$ & $\begin{array}{l}\$ \\
\$ \\
\$\end{array}$ & $\begin{array}{l}705 \\
671 \\
644\end{array}$ & $\begin{array}{l}(39.52) \text { a,c } \\
(34.39) \text { a,e } \\
(37.45) \text { c,e }\end{array}$ \\
\hline
\end{tabular}

NOTES:

$\wedge 80^{\text {th }}$ percentile value

${ }^{a}<<.05$ for difference between $25^{\text {th }}$ percentile and mean

${ }^{\mathrm{b}} p<.01$ for difference between $25^{\text {th }}$ percentile and mean

${ }^{c} p<.05$ for difference between $25^{\text {th }}$ percentile and $75^{\text {th }}$ percentile

d $p<.01$ for difference between $25^{\text {th }}$ percentile and $75^{\text {th }}$ percentile

$p<.05$ for difference between mean and $75^{\text {th }}$ percentile

${ }^{\mathrm{f}} p<.01$ for difference between mean and $75^{\text {th }}$ percentile 
Table 8: Predicted Utilization for Simulated Scenarios Using Radius-Based Measures of Provider Availability, Urban Uninsured

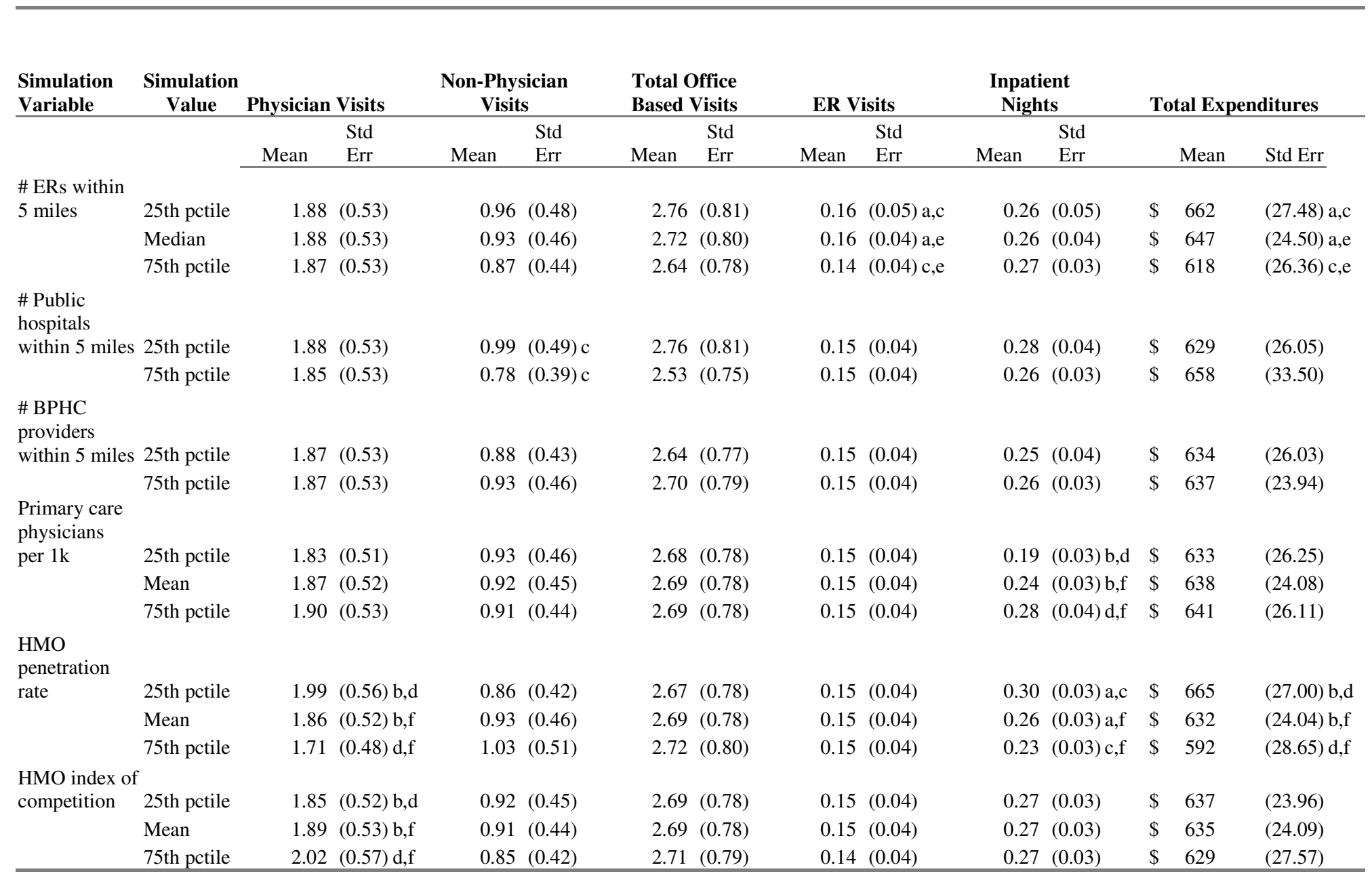




\begin{tabular}{|c|c|c|c|c|c|c|c|c|c|}
\hline \multirow[t]{3}{*}{$\begin{array}{l}\text { Public health } \\
\text { expenditures }\end{array}$} & 25th pctile & $1.93(0.54)$ & $0.78 \quad(0.38) b, d$ & $2.56(0.74)$ & $0.15(0.04)$ & $0.26(0.04)$ & $\$$ & 608 & (26.48) a,c \\
\hline & Mean & $1.86(0.52)$ & $0.93(0.45) b, f$ & $2.70(0.78)$ & $0.15(0.04)$ & $0.27(0.03)$ & $\$$ & 638 & (24.31) a,e \\
\hline & 75th pctile & $1.84(0.51)$ & $0.99(0.48) \mathrm{d}, \mathrm{f}$ & $2.75(0.80)$ & $0.15(0.04)$ & $0.27(0.03)$ & $\$$ & 649 & (25.79) c,e \\
\hline \multicolumn{10}{|l|}{ Percent } \\
\hline \multirow[t]{3}{*}{ Uninsured } & 25 th pctile & $1.87(0.53)$ & $0.91 \quad(0.44)$ & $2.64(0.77)$ & $0.17(0.05) b, d$ & $0.26(0.04)$ & $\$$ & 663 & $(31.74) \mathrm{c}$ \\
\hline & Mean & $1.87(0.52)$ & $0.92(0.45)$ & $2.70(0.78)$ & $0.15(0.04) b, f$ & $0.27 \quad(0.03)$ & $\$$ & 633 & $(24.14) \mathrm{e}$ \\
\hline & 75th pctile & $1.88(0.53)$ & $0.94 \quad(0.46)$ & $2.75(0.80)$ & $0.13(0.04) \mathrm{d}, \mathrm{f}$ & $0.27 \quad(0.03)$ & $\$$ & 610 & $(26.21) \mathrm{c}, \mathrm{e}$ \\
\hline
\end{tabular}

NOTES:

${ }^{\mathrm{a}} p<.05$ for difference between $25^{\text {th }}$ percentile and mean

b $p<.01$ for difference between $25^{\text {th }}$ percentile and mean

${ }^{c} p<.05$ for difference between $25^{\text {th }}$ percentile and $75^{\text {th }}$ percentile

d $p<.01$ for difference between $25^{\text {th }}$ percentile and $75^{\text {th }}$ percentile

$p<.05$ for difference between mean and $75^{\text {th }}$ percentile

${ }^{\mathrm{f}} p<.01$ for difference between mean and $75^{\text {th }}$ percentile 


\section{Acknowledgements}

We are grateful to Sue Polich for her expertise in working with the MEPS household survey

data, Randy Hirscher and Jill Gurvey for building the file describing the healthcare market and safety net structure, Susan Marquis for sharing her measures of safety net capacity, Beth

Eiseman for assistance with on-site work at AHRQ, and to AHRQ for their willingness to clean and add individuals' zipcode to the MEPS restricted use files, with a special thanks to Bill Carroll who facilitated the process and Ray Kuntz who provided computing support at the AHRQ Data Center. 


\section{Endnotes}

${ }^{1}$ American Hospital Association Annual Survey of Hospitals collects detailed information on hospital characteristics on a yearly basis from nearly all 5,000+ hospitals in the U.S. irrespective of AHA membership, and has a response rate of over $90 \%$.

${ }^{2}$ Whether or not an uninsured individual had a usual source of care and what that source was would have been natural other variables to analyze; however, usual source of care was not asked in every year of the MEPS and the limited data were insufficient for analysis.

${ }^{3}$ In instances where heteroskedasticity was observed in a continuous variable (such as number of miles to the closest emergency room), we calculated the smearing estimator separately according to the quartile of the continuous value.

${ }^{4}$ Full regression results are available from the authors upon request. 